\title{
Considerações críticas sobre a Lei no 11.705, de 19 de junho de 2008 ("Lei Seca”)
}

Critical considerations on the Law No. 11.705, of June 19, 2008 ("The Noble Experience")

\author{
Gustavo Silveira Machado \\ Médico, Especialista em Direito Sanitário, Consultor Legislativo da Câmara dos \\ Deputados. Brasília, Brasil.
}

Resumo: Objetivo: o artigo trata de abordar sobre os trâmites legislativos da Lei 11.705/2008, também conhecida como 'Lei Seca', que introduziu restrições ao comércio e consumo de bebidas alcoólicas às margens de rodovias. Metodologia: fez-se um estudo legislativo comparado das introduções da nova legislação ao antigo arco normativo sobre o tema, como também comparações com outros países. Resultados e Conclusões: a produção de novas leis deveria corresponder a uma real necessidade. Deveria se intensificar a fiscalização, pois a lei em seu formato anterior atendia a necessidade do controle pretendido.

Palavras-chave: lei seca, trânsito, álcool.

\begin{abstract}
Objetive: this article discuss the legislative process on the Law 11.705 / 2008, also known as "The Noble Experience Law", which introduced restrictions on trade and consumption of alcoholic beverages to highways margins. Methodology: we carried out a comparative study of legislative issues of new legislation to the old regulatory bow on the subject, as well as comparisons with other countries. Results and conclusions: the production of new laws should correspond to a real need. Should step up surveillance, because the law in its previous format met the need of the desired control.
\end{abstract}

Keywords: " the noble experience law", traffic, alcohol

Resumen: Objectivo: el artículo trata de abordar el proceso legislativo de la Ley 11.705 / 2008, también conocida como la Ley Seca, que introdujo restricciones al comercio y consumo de bebidas alcohólicas a las carreteras. Metodología: se realizó un estudio comparativo de las cuestiones legislativas de la nueva legislación para el antiguo marco regulatorio sobre la tematica, así como comparaciones con otros países. Resultados y conclusiones: la producción de nuevas leyes deberá corresponder a una necesidad real. Deben intensificar la vigilancia, ya que la ley en su formato anterior respondía a la necesidad del control deseado.

Palabras-Ilave: lei seca, tráfico, alcohol

\section{Introdução}

A Lei $n^{0}$ 11.705, de 19 de junho de 2008, que modificou o Código de Trânsito Brasileiro, foi apelidada de "lei seca" devido às restrições adicionais que introduziu sobre a comercialização e consumo de bebidas alcoólicas, proibindo sua venda às margens de rodovias e estabelecendo punições para motoristas com "qualquer taxa de álcool no sangue". 
Nos meses que se seguiram a sua publicação e entrada em vigor, registraramse simultaneamente aumento de detenções de motoristas com álcool detectado no sangue e queda nos números de acidentes de trânsito, efeitos atribuídos pela maior parte da imprensa à nova lei, mas que podem igualmente ser creditados ao incremento na fiscalização sobre os condutores e ao equipamento das polícias de trânsito com grande número de aparelhos para medição de álcool no ar expirado ("bafômetros"):

Com o fim de combater a alta incidência de acidentes de trânsito causada pela condução de veículos automotores associada ao uso de álcool, a nova lei pretendeu-se extremamente rigorosa e foi celebrada por muitos como um relevante marco político em matéria de prevenção de acidentes. E efeitos a ela atribuíveis foram sentidos de imediato, tendo-se noticiado já no primeiro final de semana de sua vigência reduções sensíveis no número de acidentes em relação a períodos anteriores.

Índices reveladores de um aparente sucesso da lei repetiram-se durante os primeiros meses que se seguiram à sua promulgação, o que possibilitou a autoridades executivas e legislativas dirigirem-se à imprensa e à opinião pública em tom vitorioso ao tratar do assunto. A sociedade brasileira, então, assimilou a mudança normativa sem considerar objeções levantadas por especialistas em direito penal e política criminal, que, por vezes, questionaram a necessidade da nova lei e a proporcionalidade das sanções por ela trazidas, bem como apontaram falhas flagrantes em sua redação.

Atualmente, porém, estatísticas já não mostram um cenário digno de exultação: segundo levantamento divulgado pela Polícia Rodoviária Federal, cresceram os números de acidentes e feridos nas estradas nos últimos doze meses em relação ao ano anterior, conquanto o número de mortos haja mantido-se praticamente estável (Taffarello, 2009).

Por outro lado, o novo texto foi alvo de pesadas críticas por parte de juristas.

Em primeiro lugar, pela introdução indevida na legislação nacional do chamado crime de perigo abstrato:

O legislador brasileiro, na tentativa de recrudescer as normas de trânsito visando a diminuição de acidentes envolvendo motoristas alcoolizados, acabou por criar uma teratologia legislativa e que vem gerando inúmeras prisões ilegais ao redor de todo o País.

$[\ldots]$

Da mera leitura comparativa do texto do art. 306 do CTB, [Código de Trânsito Brasileiro] antes e depois da Lei $\mathrm{n}^{\circ}$. 11.705/08, pode-se perceber que o legislador transformou a conduta de conduzir veículo automotivo sob a influência de álcool (na quantidade igual ou superior a 6 decigramas por litro de sangue) em crime de perigo abstrato, ou seja, retirou-se da elementar do tipo penal a necessidade de que o condutor esteja expondo a dano potencial a incolumidade de outrem. Não obstante o aplauso de toda a imprensa e de boa parte da opinião pública, segundo pesquisas divulgadas amplamente, a inovação 
legislativa nesse sentido não pode prosperar, uma vez que o art. 306, como está redigido, não é compatível com o sistema penal e os princípios constitucionais vigentes.

Diz-se isso porque o dispositivo legal em análise, ao punir criminalmente o condutor apenas e tão somente pelo fato dele estar dirigindo sob o efeito de álcool, cria uma presunção de culpa do agente, sem que ele tenha ofendido nenhum bem jurídico tutelado pelo Direito Penal (Marques, 2009).

Outra crítica frequente à nova lei diz respeito a falhas em sua redação que estariam causando efeito contrário ao pretendido, de aumento na impunidade de motoristas verdadeiramente embriagados:

[...] antes do advento da Lei 11.705/2008 o crime de embriaguez ao volante (art. 306 do CTB) não exigia nenhuma taxa de alcoolemia. Bastava a comprovação de um condutor bêbado (dirigir sob a influência do álcool) e uma direção anormal (que coloca em risco a segurança viária). Agora, depois da Lei 11.705/2008, só existe crime quando a concentração de álcool no sangue atinge o nível de 0,6 decigramas [6 decigramas]. ${ }^{1}$

Conclusão: todas as pessoas que estão sendo processadas ou mesmo que já foram condenadas pelo delito do art. 306 cometido até o dia 19.06.08, desde que tenham sido surpreendidas com menos de 0,6 decigramas [6 decigramas] de álcool por litro de sangue, foram "anistiadas". Todas! Houve abolição do delito. Em outras palavras: o que antes era delito se transformou em mera infração administrativa. Nenhuma conseqüência penal pode subsistir para esses motoristas. A lei seca trouxe lá sua surpresa: na parte criminal, beneficiou os processados ou condenados.

Prova inequívoca: não havendo prova segura de que o motorista, antes da nova lei, tinha 0,6 decigramas [6 decigramas] de álcool por litro de sangue, impõe-se a absolvição. A lei nova exige essa prova de modo incontroverso. Diante de sua ausência, só resta a absolvição. Na dúvida, absolve-se o réu (in dubio pro reo).

Lei mal redigida: se a nova lei um dia irá alcançar seu objetivo de reduzir o número de mortes no Brasil não sabemos, o que é certo, desde logo, é que ela [...] veio beneficiar milhares de motoristas embriagados que foram condenados ou que estão sendo processados pelos delitos que cometeram (Gomes, 2009).

Em um momento em que o Direito Sanitário vem-se expandindo e desenvolvendo, cremos ser importante estudar como se dá a produção das leis, seus pontos fortes e fracos e suas armadilhas, de modo a poder contribuir com o aprimoramento do processo e dos produtos finais, que criam obrigações e limitações para toda a sociedade. Este artigo trata analisa a "lei seca" e a confronta com conhecimentos técnicos e científicos sobre o tema álcool e direção.

\footnotetext{
${ }^{1} \mathrm{O}$ autor refere-se equivocadamente a "0,6 decigramas". Na verdade, o limite estipulado é de 6 decigramas ou 0,6 gramas por litro de sangue.
} 


\section{Modificações introduzidas no Código de Trânsito pela Lei 11.705/08}

A Lei 11.705/98 teve origem na Medida Provisória $n^{\circ}$ 415/2008, apresentada ao Congresso Nacional em sete de fevereiro daquele ano e cujo texto determinava unicamente a proibição de venda de bebidas alcoólicas nas margens das rodovias federais. No texto final da lei isentaram-se as áreas urbanas da restrição, e introduziram-se diversas mudanças no Código de Trânsito (Quadro 1):

\section{Quadro 1 - Modificações havidas no texto da Lei n . 9.503/97 (Código de Trânsito)} com a superveniência da Lei 11.705/08.

\begin{tabular}{|c|c|}
\hline Redação anterior & Redação após a Lei 11.705/98 \\
\hline $\begin{array}{l}\text { Art. 165. Dirigir sob a influência de } \\
\text { álcool, em nível superior a seis decigramas } \\
\text { por litro de sangue, ou de qualquer } \\
\text { substância entorpecente ou que determine } \\
\text { dependência física ou psíquica. } \\
\text { Infração - gravíssima; } \\
\text { Penalidade - multa (cinco vezes) e } \\
\text { suspensão do direito de dirigir; } \\
\text { Medida administrativa - retenção do } \\
\text { veículo até a apresentação de condutor } \\
\text { habilitado e recolhimento do documento de } \\
\text { habilitação. }\end{array}$ & $\begin{array}{l}\text { Art. 165. Dirigir sob a influência de álcool } \\
\text { ou de qualquer outra substância psicoativa } \\
\text { que determine dependência: } \\
\text { Infração - gravíssima; } \\
\text { Penalidade - multa (cinco vezes) e } \\
\text { suspensão do direito de dirigir por } 12 \text { (doze) } \\
\text { meses; } \\
\text { Medida Administrativa - retenção do } \\
\text { veículo até a apresentação de condutor } \\
\text { habilitado e recolhimento do documento de } \\
\text { habilitação. }\end{array}$ \\
\hline $\begin{array}{l}\text { Art. 276. A concentração de seis } \\
\text { decigramas de álcool por litro de sangue } \\
\text { comprova que o condutor se acha impedido } \\
\text { de dirigir veículo automotor. } \\
\text { Parágrafo único. O CONTRAN estipulará } \\
\text { os índices equivalentes para os demais } \\
\text { testes de alcoolemia. }\end{array}$ & $\begin{array}{l}\text { Art. 276. Qualquer concentração de } \\
\text { álcool por litro de sangue sujeita o condutor } \\
\text { às penalidades previstas no art. } 165 \text { deste } \\
\text { Código. } \\
\text { Parágrafo único. Órgão do Poder } \\
\text { Executivo federal disciplinará as margens de } \\
\text { tolerância para casos específicos. }\end{array}$ \\
\hline $\begin{array}{l}\text { Art. 277. Todo condutor de veículo } \\
\text { automotor, envolvido em acidente de } \\
\text { trânsito ou que for alvo de fiscalização de } \\
\text { trânsito, sob suspeita de dirigir sob a } \\
\text { influência de álcool será submetido a testes } \\
\text { de alcoolemia, exames clínicos, perícia ou } \\
\text { outro exame que, por meios técnicos ou } \\
\text { científicos, em aparelhos homologados pelo } \\
\text { CONTRAN, permitam certificar seu estado. } \\
\S 1 \text { 1o Medida correspondente aplica-se no } \\
\text { caso de suspeita de uso de substância } \\
\text { entorpecente, tóxica ou de efeitos análogos. } \\
\S 20 \text { No caso de recusa do condutor à } \\
\text { realização dos testes, exames e da perícia } \\
\text { previstos no caput deste artigo, a infração } \\
\text { poderá ser caracterizada mediante a } \\
\text { obtenção de outras provas em direito } \\
\text { admitidas pelo agente de trânsito acerca } \\
\text { dos notórios sinais de embriaguez, } \\
\text { excitação ou torpor, resultantes do consumo } \\
\text { de álcool ou entorpecentes, apresentados } \\
\text { pelo condutor. }\end{array}$ & $\begin{array}{l}\text { Art. 277. Todo condutor de veículo } \\
\text { automotor, envolvido em acidente de } \\
\text { trânsito ou que for alvo de fiscalização de } \\
\text { trânsito, sob suspeita de dirigir sob a } \\
\text { influência de álcool será submetido a testes } \\
\text { de alcoolemia, exames clínicos, perícia ou } \\
\text { outro exame que, por meios técnicos ou } \\
\text { científicos, em aparelhos homologados pelo } \\
\text { CONTRAN, permitam certificar seu estado. } \\
\S 1^{\circ} \text { Medida correspondente aplica-se no } \\
\text { caso de suspeita de uso de substância } \\
\text { entorpecente, tóxica ou de efeitos análogos. } \\
\S 2^{\circ} \text { A infração prevista no art. } 165 \text { deste } \\
\text { Código poderá ser caracterizada pelo } \\
\text { agente de trânsito mediante a obtenção de } \\
\text { outras provas em direito admitidas, acerca } \\
\text { dos notórios sinais de embriaguez, } \\
\text { excitação ou torpor apresentados pelo } \\
\text { condutor. } \\
\S 3^{\circ} \text { Serão aplicadas as penalidades e } \\
\text { medidas administrativas estabelecidas no } \\
\text { art. } 165 \text { deste Código ao condutor que se } \\
\text { recusar a se submeter a qualquer dos } \\
\text { procedimentos previstos no caput deste }\end{array}$ \\
\hline
\end{tabular}




\begin{tabular}{|c|c|}
\hline Redação anterior & Redação após a Lei 11.705/98 \\
\hline & artigo. \\
\hline $\begin{array}{l}\text { Art. 291. Aos crimes cometidos na } \\
\text { direção de veículos automotores, previstos } \\
\text { neste Código, aplicam-se as normas gerais } \\
\text { do Código Penal e do Código de Processo } \\
\text { Penal, se este Capítulo não dispuser de } \\
\text { modo diverso, bem como a Lei no } 9.099 \text {, de } \\
26 \text { de setembro de } 1995 \text {, no que couber. } \\
\text { Parágrafo único. Aplicam-se aos crimes } \\
\text { de trânsito de lesão corporal culposa, de } \\
\text { embriaguez ao volante, e de participação } \\
\text { em competição não autorizada o disposto } \\
\text { nos arts. } 74,76 \text { e } 88 \text { da Lei no } 9.099 \text {, de } 26 \\
\text { de setembro de } 1995 \text {. }\end{array}$ & $\begin{array}{l}\text { Art. 291. Aos crimes cometidos na } \\
\text { direção de veículos automotores, previstos } \\
\text { neste Código, aplicam-se as normas gerais } \\
\text { do Código Penal e do Código de Processo } \\
\text { Penal, se este Capítulo não dispuser de } \\
\text { modo diverso, bem como a Lei no } 9.099 \text {, de } \\
26 \text { de setembro de } 1995 \text {, no que couber. } \\
\S 10 \text { Aplica-se aos crimes de trânsito de } \\
\text { lesão corporal culposa o disposto nos arts. } \\
74,76 \text { e } 88 \text { da Lei no } 9.099 \text {, de } 26 \text { de } \\
\text { setembro de 1995, exceto se o agente } \\
\text { estiver: } \\
\text { I - sob a influência de álcool ou qualquer } \\
\text { outra substância psicoativa que determine } \\
\text { dependência; } \\
\text { II - participando, em via pública, de } \\
\text { corrida, disputa ou competição } \\
\text { automobilística, de exibição } \\
\text { demonstração de perícia em manobra de } \\
\text { veículo automotor, não autorizada pela } \\
\text { autoridade competente; } \\
\text { III - transitando em velocidade superior à } \\
\text { máxima permitida para a via em } 50 \mathrm{~km} / \mathrm{h} \\
\text { (cinqüenta quilômetros por hora). } \\
\S 20 \text { Nas hipóteses previstas no } \S 10 \\
\text { deste artigo, deverá ser instaurado inquérito } \\
\text { policial para a investigação da infração } \\
\text { penal. }\end{array}$ \\
\hline $\begin{array}{l}\text { Art. 296. Se o réu for reincidente na } \\
\text { prática de crime previsto neste Código, o } \\
\text { juiz poderá aplicar a penalidade de } \\
\text { suspensão da permissão ou habilitação para } \\
\text { dirigir veículo automotor, sem prejuízo das } \\
\text { demais sanções penais cabíveis. }\end{array}$ & $\begin{array}{l}\text { Art. 296. Se o réu for reincidente na } \\
\text { prática de crime previsto neste Código, o } \\
\text { juiz aplicará a penalidade de suspensão da } \\
\text { permissão ou habilitação para dirigir veículo } \\
\text { automotor, sem prejuízo das demais } \\
\text { sanções penais cabíveis. }\end{array}$ \\
\hline $\begin{array}{l}\text { Art. 306. Conduzir veículo automotor, na } \\
\text { via pública, sob a influência de álcool ou } \\
\text { substância de efeitos análogos, expondo a } \\
\text { dano potencial a incolumidade de outrem: } \\
\text { Penas - detenção, de seis meses a três } \\
\text { anos, multa e suspensão ou proibição de se } \\
\text { obter a permissão ou a habilitação para } \\
\text { dirigir veículo automotor. }\end{array}$ & $\begin{array}{l}\text { Art. 306. Conduzir veículo automotor, na } \\
\text { via pública, estando com concentração de } \\
\text { álcool por litro de sangue igual ou superior a } \\
6 \text { (seis) decigramas, ou sob a influência de } \\
\text { qualquer outra substância psicoativa que } \\
\text { determine dependência: } \\
\text { Penas - detenção, de seis meses a três } \\
\text { anos, multa e suspensão ou proibição de se } \\
\text { obter a permissão ou a habilitação para } \\
\text { dirigir veículo automotor. }\end{array}$ \\
\hline
\end{tabular}

Verifica-se que a Lei 9.503/97 já tratava com rigor quem conduzisse veículos sob o efeito de álcool, contanto que suas disposições fossem cumpridas, o que induz a um questionamento pertinente sobre a real necessidade de modificá-la.

Investiga-se aqui não a indiscutível necessidade de impedir a condução de veículos por motoristas embriagados, mas se houve base fatual para interditar e punir condutores com qualquer concentração de álcool por litro de sangue. 


\section{Acidentes de trânsito}

Toda a argumentação contra o consumo de bebidas alcoólicas por motoristas fundamenta-se no aumento do risco de acidentes, eventos não intencionais que produzem ferimentos ou danos. Acidentes de trânsito, especificamente, são os que envolvem um ou mais veículos em via pública. (IPEA/DENATRAN/ANTP, 2006)

No trânsito concorrem quatro agentes ou componentes: 1) as pessoas (motoristas, passageiros, pedestres, ciclistas); 2) os veículos, automotores ou não; 3 ) a via e o ambiente (incluindo, por exemplo, as condições climáticas e de iluminação); 4) o aparato institucional (leis, normas, policiamento etc.) e os aspectos socioambientais. Esses mesmos componentes, em menor ou maior grau, influenciam na ocorrência dos acidentes, podendo ser estudados separadamente e em conjunto. No cálculo do custo total de um acidente todos os componentes devem ser considerados. (IPEA/DENATRAN/ANTP, 2006)

Com o aumento no número de veículos em circulação ocorrido durante o século XX, aumentaram também os acidentes de trânsito, a ponto de se constituírem em grave problema de saúde pública, demandando pesquisas, campanhas e medidas governamentais para seu enfrentamento. (IPEA/DENATRAN/ANTP, 2006; OMS, 2009; Peden et al., 2004)

Os acidentes de trânsito foram, em 2002, a segunda principal causa de mortes em todo o mundo entre a população de 5 a 19 anos, e a décima causa geral, causando a perda de mais de 1.183 .000 vidas e um gasto total estimado em cerca de 518 bilhões de dólares (Peden et al., 2004). Em 2004, os acidentes já foram a nona causa geral de mortalidade ( $2,2 \%$ do total de óbitos), estimando-se que no ano de 2030 terão passado a ser a quinta principal causa (3,6\% do total de óbitos) (OMS, 2008). Somente no Brasil, no ano de 2007, ocorreram, em números absolutos, 35.155 mortes (OMS, 2009) e 124.013 internações hospitalares causadas por acidentes de trânsito, segundo o Serviço de processamento de dados do Sistema Único de Saúde (DATASUS) $)^{2}$.

Um importante índice é a taxa de mortes por acidentes trânsito por 100.000 habitantes, durante um ano. Calcula-se atualmente no Brasil uma taxa anual de 18,3 mortes/100.000 habitantes, contra 13,7 na Argentina, 16,7 na Bolívia, 13,7 no Chile,

\footnotetext{
${ }^{2}$ Informação disponível na URL: http://tabnet.datasus.gov.br/cgi/tabcgi.exe?sih/cnv/eruf.def Consultado em 11 jul. 2010.
} 
11,7 na Colômbia, 13,9 nos Estados Unidos da América, 6,0 na Alemanha, 5,4 no Reino Unido, 35,8 no Irã e 41,6 no Egito. (OMS, 2009) Ainda que o Brasil ocupe uma faixa intermediária na comparação com os outros países do mundo, apresenta uma mortalidade no trânsito superior à dos países vizinhos, indicando que há necessidade de aplicar medidas de aperfeiçoamento da segurança viária.

\section{Condução de veículos e consumo de álcool}

Os álcoois são uma classe de compostos orgânicos caracterizados pela presença de um radical hidroxila ligado à cadeia de carbono. $O$ álcool etílico ou etanol, o mais comum, compõe-se de um radical etil ou etila (cadeia de dois átomos de carbono) ao qual se liga a hidroxila. Neste trabalho, álcool e etanol são usados como sinônimos.

O álcool, contido em uma grande variedade de bebidas fermentadas ou destiladas, é a droga mais usada e abusada na sociedade moderna (Levine e Kunsman, 2000). Em excesso, é prejudicial à saúde humana, causando transtornos e enfermidades tanto agudos como crônicos, devido ao uso prolongado (Schuckit, 2005).

O aumento do consumo abusivo de álcool (alcoolismo) e suas consequências para a sociedade o tornam uma importante questão de saúde pública. (García, 1996; Barsh, 2008; Des Jarlais e Hubbard, 2002). No Brasil, estima-se que 74,6\% da população entre 12 e 65 anos e 54,3\% dos adolescentes entre 12 e 17 anos tenha consumido bebida alcoólica pelo menos uma vez na vida. Segundo a mesma estimativa, cerca de $12,3 \%$ da população seria dependente do álcool (Duarte e Stempliuk, 2010).

As bebidas alcoólicas são usualmente comercializadas e consumidas em doses. A dose típica corresponde a uma lata de cerveja de $355 \mathrm{~mL}$, uma taça de vinho de $120 \mathrm{~mL}$ ou uma dose de $40 \mathrm{~mL}$ de destilado, contendo 10 a $15 \mathrm{~g}$ de etanol puro. Depois de ingerido, o álcool é absorvido no trato gastrointestinal, e ganha a corrente sanguínea, de onde se distribui pelos tecidos do corpo. A taxa de álcool presente no sangue é denominada de alcoolemia. A alcoolemia pode ser expressa em várias unidades, sendo-o mais frequentemente em gramas por decilitro $(\mathrm{g} / \mathrm{dL}$ ou g.dL $\left.\mathrm{dL}^{-1}\right)$, ou em gramas por litro $\left(\mathrm{g} / \mathrm{L}\right.$ ou g. $\left.\mathrm{L}^{-1}\right)$. A ingestão de uma ou duas doses típicas resulta em uma alcoolemia de 0,02 a $0,03 \mathrm{~g} / \mathrm{dL}$, variando segundo a massa corporal e 
o gênero (mulheres atingem maiores alcoolemia para doses equivalentes) (Schuckit, 2005).

O álcool tem um efeito depressor sobre o sistema nervoso central, diretamente proporcional à sua concentração sanguínea. Afeta negativamente (inibe) os reflexos, os sentidos e o desempenho psicomotor geral e reduz a capacidade de realizar tarefas (Levine, 2000). O aumento no risco de acidentes por motoristas alcoolizados é fato conhecido desde pelo menos o início do século XX. O primeiro caso conhecido de proibição legal a dirigir em estado de embriaguez ocorreu em 1910, no estado norte-americano de Nova lorque (Webb e Willis, apud Pechansky et al., 2010)

Levine e Kunsman (2000, p. 104), descrevem como os efeitos do álcool sobre a fisiologia humana aumentam conforme aumenta a concentração sanguínea:

A maioria dos testes de habilidade ao volante, tanto em testes de rua como em simuladores de direção, mostram disfunção com alcoolemia de $0,05 \mathrm{~g} / \mathrm{dL}$. Estudos epidemiológicos sugerem uma associação entre desempenho prejudicado ao volante e uso de álcool. A maioria desses estudos mostra que $40 \%$ a $60 \%$ de todos os motoristas fatalmente feridos têm alcoolemia de $0,1 \mathrm{~g} / \mathrm{dL}$ ou maior e que $30 \%$ a $40 \%$ desses têm alcoolemia acima de $0,15 \mathrm{~g} / \mathrm{dL}$. É importante notar que uma relação de causa e efeito não pode ser estabelecida por estudos retrospectivos e, portanto, não é possível afirmar, com base nesses estudos, que a presença de álcool foi o fator causal nos acidentes. A amplitude dos efeitos do álcool no comportamento pode ser grosso modo categorizada conforme a alcoolemia como segue:

- <0,05 g/dL (dose baixa) - loquacidade aumentada, discreta excitação, atenção diminuída, inibições diminuídas e pequena disfunção de algumas habilidades motoras em alguns indivíduos;

- de 0.05 a $0,10 \mathrm{~g} / \mathrm{dL}$ (dose moderada) - loquaz, animado, mais ruidoso, espalhafatoso e depois sonolento, mais confiante, mais disposto a correr riscos, disfunção de habilidades psicomotoras (orientação, vigilância, atenção dividida, tempo de reação etc.);

- de 0,10 a 0,30 g/dL (dose elevada) - náusea e vômitos podem ocorrer seguidos de letargia, ataxia, fala empastada, diplopia, marcha vacilante, desorientação e habilidades psicomotoras grosseiramente afetadas;

- de 0,30 a 0,50 g/dL (dose alta) - estupor, disfunção visual, resposta marcadamente reduzida a estímulos (mesmo dolorosos) e marcada incoordenação muscular. Coma e posteriormente morte devido a depressão respiratória são esperados com alcoolemia superior a 0,4 $\mathrm{g} / \mathrm{dL}$ em indivíduos não dependentes de álcool. Note-se que indivíduos altamente tolerantes (como alcoolistas crônicos) podem não experimentar ou parecer não experimentar muitos dos efeitos mais sérios associados a altas concentrações de álcool no sangue, mas todos os indivíduos experimentam os efeitos deletérios sobre a cognição e o julgamento com alcoolemias maiores que $0.08 \mathrm{~g} / \mathrm{dL}$. 
De acordo com estudo realizado em 1964 no estado norte-americano de Michigan, motoristas alcoolizados têm risco maior de sofrer acidentes, tão mais acentuado quanto maior a alcoolemia. Avalia-se que o risco começa a aumentar significativamente com $0,04 \mathrm{~g} / \mathrm{dL}$, é cinco vezes maior com $0,10 \mathrm{~g} / \mathrm{dL}$, cerca de 20 vezes maior com $0,14 \mathrm{~g} / \mathrm{dL}$, e cento e quarenta vezes maior com $0,24 \mathrm{~g} / \mathrm{dL}$. (Global Road Safety Partnership, 2007)

Estatísticas de diversas fontes são usadas para dar suporte às políticas de combate ao uso bebidas alcoólicas por motoristas. No Brasil, o estudo mais abrangente até o momento foi o realizado em 1997 em quatro capitais de estado, no qual 27,2\% das vítimas de acidentes de trânsito apresentaram alcoolemia superior a 0,06 g/dL (Galduróz e Caetano, 2004) Não discriminava, contudo, quantas das vítimas, alcoolizadas ou não, eram motoristas, quantos passageiros e quantos pedestres.

Outro estudo, realizado em hospitais de Porto Alegre em 2009, (Soibelman et al., 2010) revelou que $8,3 \%$ das vítimas apresentaram positividade para álcool, sendo $9,1 \%$ entre os pedestres, $9,2 \%$ entre os passageiros e $7,8 \%$ entre os condutores.

Um estudo feito sobre vítimas fatais de acidentes na África do Sul revelou também uma incidência elevada de alcoolemia positiva entre pedestres, como mostra a Tabela 1.

Tabela 1 - Proporção (\%) de pedestres vítimas fatais de acidentes de trânsito segundo a alcoolemia (g/dL). África do Sul, 2007.

\begin{tabular}{lccccc}
\hline & Zero & $0,01-0,04$ & $0,05-0,14$ & $0,15-0,24$ & $\geq 0,25$ \\
\hline Pedestres & 37,5 & 5,4 & 12,0 & 20,5 & 24,7 \\
\hline Passageiros & 62,6 & 4,7 & 14,0 & 13,7 & 5,0 \\
\hline Condutores & 48,2 & 5,3 & 18,2 & 18,8 & 9,5 \\
\hline Ciclistas & 61,3 & 3,2 & 15,1 & 14,0 & 6,5
\end{tabular}

Fonte: Global Road Safety Partnership, 2007.

A presença de motoristas alcoolizados em acidentes, por sua vez, não significa necessariamente que eles os tenham causado. Para definir qual ou quais dos envolvidos foram responsáveis por um acidente, alguns pesquisadores desenvolveram técnicas de "análise de responsabilidade", que levam em conta as circunstâncias do acidente, sua dinâmica e a ação dos envolvidos. (Kuruc et al., 2009) 
Os resultados de um estudo realizado com a análise de responsabilidade figuram na Tabela 2. A responsabilidade pelo acidente e a incidência de alcoolemia foram determinadas separadamente e tabuladas.

Tabela 2 - Responsabilidade pelo acidente de trânsito relacionada com intoxicação alcoólica no tocante a categorias de participantes no trânsito.

\begin{tabular}{lcccc}
\hline Responsabilidade & \multicolumn{2}{c}{ Alcoolemia positiva } & \multicolumn{2}{c}{ Alcoolemia negativa } \\
\cline { 2 - 5 } pelo acidente & $\mathrm{n}^{\circ}$. & $\%$ & $\mathrm{n}^{\circ}$. & $\%$ \\
\hline Motoristas & 41 & 91,1 & 61 & 66,3 \\
Pedestres & 37 & 82,2 & 34 & 50,7 \\
Ciclistas & 18 & 90,0 & 6 & 31,6 \\
\hline Total & 96 & 87,3 & 101 & 56,7 \\
\hline Fonte: & & & &
\end{tabular}

Os resultados, portanto, reconfirmam que motoristas alcoolizados têm maior probabilidade de causar acidentes de trânsito. É importante notar, contudo, que: 1) os indivíduos estudados apresentaram alcoolemias bastante elevadas: na média total, determinou-se $0,191 \mathrm{~g} / \mathrm{dL}(0,166 \mathrm{~g} / \mathrm{dL}$ entre os motoristas, $0,207 \mathrm{~g} / \mathrm{dL}$ entre os pedestres e 0,2 g/dL entre os ciclistas chegando a máximos de 0,355 g/dL, 0,446 g/dL e $0,378 \mathrm{~g} / \mathrm{dL}$ ); 2) a média de alcoolemia dos motoristas que testaram positivamente, de $0,166 \mathrm{~g} / \mathrm{dL}$, corresponde a um avançado grau de intoxicação alcoólica, no qual, segundo as estimativas apresentadas por outros autores, o risco de colisão seria cerca de oitenta vezes maior (Global Road Safety Partnership, 2007).

É fato que a embriaguez ao volante deve ser evitada e, se for o caso, punida. A grande maioria dos países já adota, há mais ou menos tempo, restrições ao uso de álcool por motoristas, mediante limites legais de alcoolemia (Global Road Safety Partnership, 2007). A Tabela 3 mostra os limites de alcoolemia para motoristas adotados em diversos países.

Tabela 3: Níveis de alcoolemia permitidos para motoristas em diversos países.

\begin{tabular}{lc|lc}
\hline País & Alcoolemia $(\mathrm{g} / \mathrm{dL})$ & País & Alcoolemia $(\mathrm{g} / \mathrm{dL})$ \\
\hline Alemanha & 0,05 & Lesoto & 0,05 \\
Austrália & 0,05 & Luxemburgo & 0,05 \\
Áustria & 0,05 & Holanda & 0,05 \\
Bélgica & 0,05 & Nova Zelândia & 0,08
\end{tabular}




\begin{tabular}{lc|lc}
\hline País & Alcoolemia $(\mathrm{g} / \mathrm{dL})$ & País & Alcoolemia $(\mathrm{g} / \mathrm{dL})$ \\
\hline Benin & 0,08 & Noruega & 0,05 \\
Botsuana & 0,08 & Portugal & 0,05 \\
Brasil & 0,00 & Federação Russa & 0,02 \\
Canadá & 0,08 & África do Sul & 0,05 \\
Costa do Marfim & 0,08 & Espanha & 0,05 \\
República Tcheca & 0,05 & Suazilândia & 0,08 \\
Dinamarca & 0,05 & Suécia & 0,02 \\
Estônia & 0,02 & Suíça & 0,08 \\
Finlândia & 0,05 & Uganda & 0,15 \\
França & 0,05 & Reino Unido & 0,08 \\
Grécia & 0,05 & Tanzânia & 0,08 \\
Hungria & 0,05 & Estados Unidos & 0,08 ou $0,10^{*}$ \\
Irlanda & 0,08 & Zâmbia & 0,08 \\
Itália & 0,05 & Zimbábue & 0,08 \\
Japão & 0,00 & & \\
Fonte: Global Road Safety Partnership, 2007. & varia de estado para estado & \\
& 0.04 &
\end{tabular}

O limite de $0,05 \mathrm{~g} / \mathrm{dL}$, adotado pela maioria dos países listados na tabela, é compatível com a evidência recorrente na literatura revista, segundo a qual somente a partir de 0,04 ou $0,05 \mathrm{~g} / \mathrm{dL}$ os efeitos da intoxicação alcoólica começam a se tornar mais evidentes e significar risco.

\section{Outros fatores de risco}

O consumo de álcool não é o único fator de aumento de probabilidade de ocorrência de acidentes. Outros fatores, como pequenos incrementos na velocidade de deslocamento do veículo, podem ser tão ou mais significativos que a ingestão de álcool, como mostra a tabela a seguir (Tabela 4), que compara o aumento do risco de acidentes em velocidades crescentes com motoristas sóbrios e concentrações crescentes de álcool no sangue. 
Tabela 4: Comparação de riscos relativos de acidentes para aumento de velocidade e consumo de álcool.

\begin{tabular}{cccc}
\hline $\begin{array}{c}\text { Velocidade } \\
(\mathrm{Km} / \mathrm{h})\end{array}$ & $\begin{array}{c}\text { Velocidade } \\
\text { (risco relativo) }\end{array}$ & $\begin{array}{c}\text { Alcoolemia } \\
(\mathrm{g} / \mathrm{dL})\end{array}$ & $\begin{array}{c}\text { Alcoolemia } \\
\text { (risco relativo) }\end{array}$ \\
\hline 60 & 1,0 & 0,00 & 1,0 \\
65 & 2,0 & 0,05 & 1,8 \\
70 & 4,2 & 0,08 & 3,2 \\
75 & 10,6 & 0,12 & 7,1 \\
80 & 31,8 & 0,21 & 30,4 \\
\hline
\end{tabular}

Fonte: Peden, 2004.

Assim como a presença de álcool no sangue, identificam-se outros fatores que aumentam a probabilidade de acidentes. Dos que afetam diretamente o desempenho individual destacam-se a juventude e inexperiência do motorista, uso de drogas psicoativas (lícitas ou ilícitas), cansaço e sonolência (OMS, 2004). O comportamento ao volante também tem importância destacada.

Panitz (1999) lista, ademais de fatores de ordem física e sensorial, vários fatores psicológicos que afetam o comportamento do motorista: motivação, nível de inteligência, processo de aprendizagem, atenção, atitude face ao risco, atitude face à regulação, atitude de impaciência e irritação, grau de maturidade, reações condicionadas e diferenças individuais, cada um deles podendo interferir no desempenho. Por exemplo, um motorista apressado (motivação) tende a exceder a velocidade adequada à via e ignorar precauções de segurança, assim como um motorista jovem e arrojado tende a assumir riscos maiores.

O comportamento de risco pode ser classificado basicamente em dois tipos: os erros, que são falhas involuntárias, e as violações, que são infrações deliberadas, sendo geralmente aceito que o uso de álcool aumenta a probabilidade de ocorrência de ambos. (Faller et al., 2010) Em estudo realizado na cidade de Porto Alegre (RS), comparou-se a incidência dos dois tipos de comportamento entre motoristas com alcoolemia negativa e positiva. A Tabela 5 exibe os resultados desse estudo. 
Tabela 5: Prevalência (\%) de comportamentos de risco no trânsito segundo a alcoolemia positiva ou negativa do motorista.

\begin{tabular}{lcccc}
\hline & Erro & Violação & $\begin{array}{c}\text { Violação } \\
\text { agressiva }\end{array}$ & $\begin{array}{c}\text { Viol. agressiva } \\
\text { interpessoal }\end{array}$ \\
\hline Alcoolemia - & 88,7 & 84,8 & 73,7 & 60,4 \\
Alcoolemia + & 92,5 & 79,2 & 67,9 & 60,4 \\
\hline
\end{tabular}

Fonte: Faller, 2010.

Afirmam os autores, ao expor as conclusões obtidas com o estudo:

[...] No que compete aos comportamentos de risco para acidentes de trânsito, não foram encontradas diferenças estatisticamente significativas entre os grupos estudados. Cabe salientar, entretanto, que a proporção de erros e violações foi bastante alta na amostra estudada, o que expõe um problema de bastante relevância para a saúde pública do país, independente do consumo de álcool e substâncias dos condutores (Faller, 2010).

Há outros autores que se referem a um comportamento de risco, que independe do uso de álcool. Hedlund (1994), estudando o efeito das medidas de restrição de uso de álcool por motoristas, classificou-os em três grupos:

1) Motoristas "normais" que bebem socialmente, e por não estimarem adequadamente os efeitos do álcool têm risco aumentado de acidentes. Abstendo-se de seu uso, o risco tende a normalizar-se.

2) Motoristas "de alto risco". São bebedores contumazes, para quem o abuso de álcool seria apenas mais uma manifestação de um comportamento de risco ou um meio voluntário de remover as inibições. Para estes, a abstinência não reduz em muito o risco de acidentes.

3) Alcoolistas, para quem abster-se do uso de álcool reduziria em muito o risco de acidentes, mas que para isso necessitariam uma completa mudança de vida.

Hedlund afirma ainda que:

[...] Os motoristas "de alto risco" são talvez o grupo mais difícil de afetar. Detenção, até mesmo prisão e punição podem ter pouca influência sobre seu comportamento. Algum comportamento de alto risco é superado à medida que os motoristas amadurecem. No entanto, uma vez que o comportamento de alto risco está tão profundamente arraigado nas personalidades de alguns deles, qualquer mudança requer medidas bem mais amplas que as disponíveis a [os agentes de] segurança do trânsito.

É lícito considerar que a combinação de dois ou mais fatores (por exemplo, álcool + drogas ou álcool + inexperiência) tenha o efeito de aumentar o risco de 
acidente além do que o fazem isoladamente. De fato, há evidências de que motoristas inexperientes são afetados mais intensamente pelo álcool:

Considerando a população de condutores em geral, uma vez que a alcoolemia é superior a zero, o risco de acidente de trânsito começa a aumentar de maneira significativa quando a alcoolemia atinge 0,04 $\mathrm{g} / 100 \mathrm{ml}$.

Os condutores jovens e sem grande experiência ao volante, ao dirigirem com uma alcoolemia de $0,05 \mathrm{~g} / 100 \mathrm{ml}$ correm um risco de acidente 2,5 vezes superior ao risco a que estão expostos os condutores mais experientes.

Jovens adultos na faixa etária de 20-29 anos estão expostos a um risco superior estimado em 3 vezes o risco a que estão sujeitos os condutores com idade a partir de 30 anos, seja qual for a alcoolemia.

Adolescentes ao volante estão expostos a um risco de acidente fatal 5 vezes superior ao risco a que estão expostos os condutores com idade a partir de 30 anos, seja qual for a alcoolemia. (Global Road Safety Partnership, 2007, p.13)

Em 1983, os estados norte-americanos do Maine e da Carolina do Norte foram pioneiros em estabelecer limites legais menores para condutores jovens, e em 1995 foi editada lei federal compelindo todos os estados a fixar o limite de $0.02 \mathrm{~g} / \mathrm{dL}$ para motoristas menores de 21 anos (Shults et al., 2001).

Em 2001, a Comissão das Comunidades Europeias editou uma recomendação oficial segundo a qual todos os Estados membros deveriam adotar o limite máximo de $0,05 \mathrm{~g} / \mathrm{dL}$ de alcoolemia para todos os motoristas, exceto os condutores inexperientes, motociclistas, condutores de veículos de grande porte e condutores de veículos transportando mercadorias perigosas, para quem seria aplicado o limite máximo de 0,02 g/dL (Comissão das Comunidades Europeias, 2001).

\section{Determinação da alcoolemia}

Pode-se aventar como motivo para a concentração das atenções no álcool a fácil mensurabilidade da sua presença em comparação com aspectos comportamentais, estados patológicos e mesmo com o uso de outras drogas.

O álcool pode ser dosado no sangue, na urina, na saliva, no suor e no ar expelido pelos pulmões (Limberger et al., 2010). No Brasil, a pesquisa de álcool e outras drogas no organismo do motorista é normatizada pela Resolução o 206 do CONTRAN, que determina que a confirmação será feita pelo menos por um dos meios: exame de sangue, teste de ar alveolar, exame clínico por médico perito ou 
exame realizado por laboratório especializado (Brasil, 2006). O meio mais facilmente disponível, não invasivo e que requer treinamento mínimo, podendo ser usado por policiais e agentes de trânsito, é o chamado bafômetro, destinado a determinar somente a presença de álcool no ar alveolar.

Há diversos modelos de bafômetros, que empregam diferentes tecnologias. Todos são, em alguma proporção, sujeitos a erro. Um exemplo de fator comum que afeta sua precisão é a variação da temperatura ambiente. Os aparelhos devem ser calibrados previamente ao uso. Alguns deles baseiam-se na detecção no ar alveolar do radical etil, presente no álcool (etanol, etil-álcool), mas também são sensibilizados pelo radical metil, com um carbono a menos na molécula. A respiração normal contem mais de cem moléculas diferentes, e 70 a 80 por cento contêm o radical metil. Desta forma, o aparelho pode acusar positivamente sem a presença de etanol. A leitura pode ser falsamente positiva também para indivíduos diabéticos ou em jejum prolongado, que têm níveis sanguíneos (e no ar alveolar) bastante altos de acetona, reconhecida como etanol por alguns aparelhos. Também já foi relatado em pesquisa que a ingestão de vários tipos de pães pode gerar leituras equivalentes e até 0,05 $\mathrm{g} / \mathrm{dL}$, e mesmo profissionais que trabalhem com produtos voláteis, como pintores podem testar positivamente sem a ingestão de álcool (Hanson, 200-). Além disso, já se determinou que, em condições normais, um indivíduo tem uma produção endógena que pode chegar a $30 \mathrm{~g}$ de etanol e $0,6 \mathrm{~g}$ de metanol por dia, podendo ser até duplicada pela ingestão de frutas contendo pectina, como a maçã, gerando alcoolemia detectável (Lindinger et al., 1998).

A dose típica, como visto, contém $15 \mathrm{~g}$ de etanol puro. Portanto, a produção endógena de etanol, dependendo da dieta, pode chegar ao equivalente a quatro doses por dia.

\section{Conclusões}

As bebidas alcoólicas fazem parte da história humana e de sua cultura, fazendo parte de cerimônias, festejos e rituais religiosos. Há, pois, que se diferenciar entre o seu uso normal e o abusivo. O uso abusivo de álcool (alcoolismo) episódico ou crônico é, inquestionavelmente, um sério problema de saúde pública e como tal deve ser enfrentado pelos meios disponíveis. 
A condução de veículos automotores por indivíduos embriagados, com comprometimento das funções psíquicas ou motoras, é comprovadamente um risco e deve ser impedida, se necessário mediante severas punições, com o objetivo bem definido de evitar acidentes de trânsito e suas consequências. No entanto, não nos foi possível delimitar o risco de ingerir bebidas em pequenas quantidades que não comprometem o desempenho neuropsicomotor, nem o objetivo de punir e tolher os direitos de motoristas que apresentem mínimas quantidades de álcool na corrente sanguínea.

A produção de novas leis deveria corresponder a uma real necessidade. A real necessidade, neste caso, seria fazer cumprir, mediante severa e intensiva fiscalização, a lei em seu formato anterior.

\section{Referências}

BARSCH, Gundula. Alcohol Consumption. In: KIRCH, Wilhelm (org.) Encyclopedia of public health. Nova lorque: Springer, 2008. ISBN 978-1-4020-5613-0

BRASIL. Lei $n^{\circ}$. 11.705, de 19 de junho de 2008. [on line] [Disponível na Internet na URL:

http:/intranet2.camara.gov.br/internet/legislacao/legin.html/visualizarTextoAtualizado? idNorma $=576771$ Consultado em 12 nov. 2009].

BRASIL. Lei no 9.503, de 23 de setembro de 1997. [on line] [Disponível na internet na URL: $\quad$ http://www2.camara.gov.br/legin/fed/lei/1997/lei-9503-23-setembro-1997372348-norma-pl.html Consultado em 8 jun. 2010].

BRASIL. Lei Complementar $n^{\circ}$. 95, de 26 de fevereiro de 1998. [on line] [Disponível na internet na

URL:

http://www2.camara.gov.br/internet/legislacao/legin.html/visualizarNorma.html?ideNor $\underline{m a}=363948$ \&PalavrasDestaque $=$ Consultado em 17 mar. 2010].

BRASIL, Conselho Nacional de Trânsito. Resolução no 206, de 20 de outubro de 2006. [on line] [Disponível na internet na URL: http://www.denatran.gov.br/download/Resolucoes/Resolucao206 06.pdf Consultado em 15 jul. 2010].

COMISSÃO DAS COMUNIDADES EUROPEIAS. Recomendação da Comissão de 17 de janeiro de 2001. Diário Oficial das Comunidades Europeias, edição de 14/2/2001.

DES JARLAIS, Don C.; HUBBARD, Robert L. Alcohol and drug abuse. In: DETELS, Roger et al. (orgs.) Oxford textbook of public health. Oxford: Oxford University Press, 2002. ISBN 13: 9780199218707

DUARTE, Paulina do Carmo V.; STEMPLIUK, Vladimir de Andrade. O projeto de pesquisa como elemento na construção da política nacional sobre o álcool. In: PECHANSKY, Flavio; DUARTE, Paulina do Carmo Arruda Vieira; DE BONI, Raquel Brandini. Uso de bebidas alcoólicas e outras drogas nas rodovias brasileiras e outros estudos. Porto Alegre: Secretaria Nacional de Políticas sobre Drogas, 2010. 
FALLER, Sibele et al. Psicopatologia e comportamento de risco em motoristas privados e profissionais no Brasil. In: PECHANSKY, Flavio; DUARTE, Paulina do Carmo Arruda Vieira; DE BONI, Raquel Brandini. Uso de bebidas alcoólicas e outras drogas nas rodovias brasileiras e outros estudos. Porto Alegre: Secretaria Nacional de Políticas sobre Drogas, 2010.

GALDURÓZ, José Carlos F.; CAETANO, Raul. Epidemiologia do uso de álcool no Brasil. Revista Brasileira de Psiquiatria, 26 (Supl. I): 3-6, 2004. ISSN 1516-4446

GARCÍA, Julio José Galiano. Alcoholismo-prevención. In: MACÍAS GUTIÉRREZ, Bernardo E. et al. (orgs.). Salud Pública y educación para la salud. Las Palmas: ICEPSS, 1996. ISBN 0185-2760

GLOBAL ROAD SAFETY PARTNERSHIP. Beber e dirigir: manual de segurança viária para profissionais de trânsito. Genebra: Global Road Safety Partnership, 2007. ISBN 1832-9497

GOMES, Luiz Flávio. Lei seca: já não evita mortes e ainda gera impunidade. Informativo Jurídico Consulex. Brasília, 23(37):23-26, set., 2009. ISSN 1519-8065

HANSON, David J. Breath analyzer accuracy. [on line] [Disponível na internet na URL: http://www2.potsdam.edu/hansondj/Drivinglssues/1055505643.html Consultado em 15 jul. 2010].

HEDLUND, J. H. If they didn't drink, would they crash anyway? The role of alcohol in traffic crashes. Alcohol, Drugs and Driving, 110(2):115-125, 1994. ISSN 1937-1888,

IPEA / DENATRAN / ANTP. Impactos sociais e econômicos dos acidentes de trânsito nas rodovias brasileiras: Relatório executivo. Brasília: IPEA, 2006.

KURUC et al. The responsibility of alcohol-impaired road users in fatal road traffic accidents. Bratisi Lek Listy, 110(12): 802-806, 2009. ISSN 0006-9248

LEVINE, B.; KUNSMAN, G. W. Alcohol / Interpretation. In: SIEGEL, Jay; KNUPFER, Geoffrey; SAUKKO, Pekka (orgs.) Encyclopedia of forensic sciences, Nova lorque: Academic Press, 2000. ISBN 9780123821652

LIMA, José Mauro Braz de. Alcoologia: o alcoolismo na perspectiva da saúde pública. Rio de Janeiro: Medbook, 2008. ISBN 9781451175363.

LIMBERGER et al. Testes toxicológicos para aferição de substâncias psicoativas em condutores. In: PECHANSKY, Flavio; DUARTE, Paulina do Carmo Arruda Vieira; DE BONI, Raquel Brandini. Uso de bebidas alcoólicas e outras drogas nas rodovias brasileiras e outros estudos. Porto Alegre: Secretaria Nacional de Políticas sobre Drogas, 2010.

MARQUES, Paulo Luciano Maia. Da inexistência de crime na condução de veículo automotor sob efeito de álcool. Informativo Jurídico Consulex. Brasília, 23(34):11-12, agosto, 2009. ISSN 1519-8065

NASCIMENTO, Rogério José Bento Soares do. Abuso do poder de legislar: controle judicial da legislação de urgência no Brasil e na Itália. Rio de Janeiro: Lumen Juris, 2004. ISBN 857387552

ORGANIZAÇÂO MUNDIAL DA SAÚDE (OMS). Global status report on road safety: time for action. Genebra: OMS, 2009. 
ORGANIZAÇÂO MUNDIAL DA SAÚDE (OMS). World health statistics 2008. Genebra: OMS, 2008.

PANITZ, Mauri Adriano. A segurança viária e o fator humano: verificação da presença de álcool - direção no sistema de transporte rodoviário do Rio Grande do Sul. Porto Alegre: Dissertação defendida junto ao Programa de Pós-graduação em Engenharia de produção da UFRGS, 1999.

PECHANSKY, Flavio; DUARTE, Paulina do Carmo Arruda Vieira; DE BONI, Raquel Brandini. Uso de bebidas alcoólicas e outras drogas nas rodovias brasileiras e outros estudos. Porto Alegre: Secretaria Nacional de Políticas sobre Drogas, 2010.

PEDEN, Margie et al. World Report on Road Traffic Injury Prevention. Genebra: OMS, 2004.

SCHUCKIT, Marc A. Alcohol and alcoholism. In: KASPER, Dennis L. et al. (orgs.). Harrison's principles of internal medicine. Nova lorque: McGraw-Hill, 2005. ISBN 13: 978-0071748896

SHULTS, Ruth A. et al. Reviews of evidence regarding interventions to reduce alcohol-impaired driving. American Journal of Preventive Medicine, 21(48): 2001. ISSN 0749-3797. Disponível em < http://www.sciencedirect.com/science/article/pii/S0002934314003970> Acesso em 24.nov.2014.

SILVA, Cláudio Jerônimo da; CASTRO, Luis André P. G.; LARANJEIRA, Ronaldo. Dependência e uso nocivo do álcool. In: BORGES, Durval Rosa et al. (orgs.). Atualização Terapêutica 2005. São Paulo: Artes Médicas, 2005. ISBN 0004-2730

TAFFARELLO, Rogério Fernando. Lei seca: simbolismo penal e ineficácia social. $L$ \& C - Revista de Administração Pública e Política. Brasília, 12(134):27, ago., 2009. ISSN 0034-7612 